\section{Efeitos da regulação federal sobre o financiamento da saúde}

\author{
The effects of Brazilian Federal regulation \\ on health financing
}

\author{
${ }^{1}$ Escola de Filosofia, Letras \\ e Ciências Humanas, \\ Universidade Federal de São \\ Paulo, São Paulo, Brasil. \\ Correspondência \\ D. A. Vazquez \\ Escola de Filosofia, Letras \\ e Ciências Humanas \\ Universidade Federal de \\ São Paulo. \\ Estrada do Caminho Velho \\ 333, Guarulhos, SP 07252-312, \\ Brasil. \\ dvazquez@unifesp.br
}

\section{Abstract}

The article aimed to analyze the impacts of earmarking revenues and conditional transfers on the supply of health financing in Brazil. After analyzing the role of these Federal regulation mechanisms on decentralized healthcare administration, the article verified the effects on total expenditure in health and disaggregated by level of government, evaluated whether transfers by the Unified National Health System (SUS) were consistent with the evolution in the decentralized supply, and measured the inequalities in per capital health spending by municipalities. The conclusions showed the complementary relationship between earmarking revenues and conditional transfers according to supply, which: (1) increased the share of State and Municipal governments in health financing; (2) provided incentives for the decentralization of primary care according to Federal guidelines; and (3) reduced the inequalities between municipalities in per capita health expenditures.

Health Financing; Government Regulation; Decentralization; Primary Health Care

\section{Introdução}

Com o objetivo de viabilizar mais recursos para a saúde, de garantir prioridade à atenção básica e promover sua efetiva descentralização, novas regras e incentivos foram introduzidos no financiamento da saúde para que os governos subnacionais ampliassem o percentual de recursos destinados à saúde e assumissem a oferta do atendimento básico e de programas específicos, nos moldes definidos pelo governo federal. Com isso, a autonomia decisória dos governos estaduais e municipais passou a ser afetada por regras e incentivos estabelecidos, a fim de obter a cooperação dessas esferas de governo e de definir um padrão nacional de execução local dos programas desenhados centralmente. É o que se entende aqui por regulação federal.

Segundo Castro \& Machado 1 (p. 694), “apesar da execução direta de ações e serviços de atenção primária à saúde ser atribuição da esfera municipal, o Ministério da Saúde tem papel relevante na determinação desta política em âmbito nacional, por ser um importante órgão formulador e financiador das políticas de saúde e pelo caráter indutor da política federal de incentivos para a atenção primária à saúde". Tal caráter indutor estabelece uma relação direta entre União e municípios na política de atenção básica à saúde 2 , com o governo federal definindo diretrizes e desenhos dos programas, norteando as ações dos municípios que são responsáveis pela execução. 
Para cada tipo de política, a regulação federal foi constituída por mecanismos diferenciados, com o intuito de gerar os incentivos corretos para a adesão dos governos locais. Portanto, era necessário considerar as especificidades e a participação de cada esfera de governo na oferta e no financiamento das políticas em reforma. Além disso, a introdução da regulação deveria prever o grau de mudança necessário no aparato legal - emenda constitucional, legislação complementar ou portaria ministerial - para a implantação dos mecanismos institucionais formulados.

Na área da saúde, a partir de 1995, observouse a ênfase na regulação dos sistemas estaduais e municipais que, conforme Machado et al. 3 (p. 2370), visavam estabelecer "coordenação intergovernamental, com base em prioridades ou metas acordadas". Destacam-se dois mecanismos de regulação federal no financiamento dessa política: (i) a nova lógica dos repasses do SUS, definidas pelas Normas Operacionais Básicas de 1993 e de 1996 (NOB 01/93 e NOB 01/96), visando disponibilizar recursos em proporção à oferta descentralizada das ações de atenção básica à saúde e; (ii) a vinculação de receitas, estabelecida pela Emenda Constitucional no. 29 (EC 29) em setembro de 2000, a fim de ampliar a participação dos governos estaduais e municipais no gasto total em saúde. Este artigo analisará como estes dois mecanismos foram implantados e se os resultados esperados foram alcançados, verificando os impactos sobre o gasto em saúde, com destaque para a participação dos municípios no financiamento desta política.

A vinculação de recursos à saúde contribui para a ampliação gradual do gasto até o alcance do percentual mínimo estabelecido e, a partir daí, espera-se maior uniformidade do patamar aplicado em saúde sobre a receita total de cada governo ${ }^{4}$. A vinculação de receitas impede que os municípios apliquem um percentual inferior ao mínimo definido constitucionalmente, contribuindo para a redução das desigualdades horizontais no gasto municipal em saúde, ainda que o nível deste gasto esteja vinculado à disponibilidade de receita, cuja base ainda permanece bastante desigual.

Complementarmente, as transferências de recursos federais (SUS) são norteadas pelo tamanho da população e o tipo de adesão dos municípios às políticas de saúde desenhadas pelo governo federal, além de prever recursos adicionais vinculados à oferta de programas específicos, como o Programa Saúde da Família (PSF), fornecendo estímulos para que os governos municipais assumam a oferta desses programas, de acordo com diretrizes definidas pelo Ministério da Saúde. Espera-se que essas transferências condicionadas disponibilizem recursos em proporção à oferta descentralizada de serviços de atenção básica à saúde e, ao mesmo tempo, contribuam para a redução das desigualdades, já que os repasses são norteados por critérios próprios da política.

O objetivo deste artigo é analisar os impactos dos mecanismos de regulação federal - vinculação de receitas e transferências condicionadas - sobre o financiamento em saúde. Para tanto, optou-se por (i) verificar a evolução do gasto total em saúde, desagregado por esfera de governo; (ii) avaliar se os repasses do SUS acompanharam a evolução do atendimento básico em saúde prestado pelos municípios e; (iii) mensurar as desigualdades no gasto per capita em saúde aplicado pelos municípios brasileiros. Juntas, vinculação e transferências condicionadas contribuem para elevar o gasto em saúde e reduzir as desigualdades horizontais no financiamento dessa política?

As conclusões deste estudo mostram que o patamar mínimo de gasto estabelecido pela vinculação de receitas e as condicionalidades impostas para os repasses do SUS resultaram no aumento da participação dos governos subnacionais no financiamento e na oferta do atendimento básico em saúde (especialmente, dos municípios), como também na redução das desigualdades horizontais quanto aos recursos aplicados em saúde pelos municípios.

Notou-se uma complementaridade entre os dois mecanismos de financiamentos estudados: os incentivos financeiros estimulam a descentralização dos serviços, mas não cobrem integralmente os custos de oferta dos programas, exigindo contrapartidas municipais de recursos próprios, as quais são viabilizadas pela vinculação de receitas. Após a adesão dos municípios, verificou-se que os valores que norteiam as transferências da União não foram corrigidos adequadamente, o que exigiu maior aporte de recursos próprios municipais.

\section{Metodologia}

Primeiramente, o presente artigo abordará as mudanças nas regras de financiamento da política de saúde, as alterações nas relações intergovernamentais e a adequação dessas para que se promovam o aumento do gasto em saúde, a compatibilização entre recursos e encargos assumidos pelos municípios e a redução das desigualdades no gasto municipal em saúde.

Após a análise dos aspectos institucionais e federativos da regulação federal sobre a política de saúde, buscar-se-á avaliar os resultados ob- 
tidos pelas regras e incentivos implementados a partir da segunda metade dos anos 1990. Pela análise de dados sobre o gasto em saúde e sobre a oferta municipal de serviços de atenção básica, pretende-se responder às seguintes questões: " $A$ vinculação de receitas elevou o gasto em saúde?", "Os repasses do SUS foram efetuados em proporção à oferta de atenção básica?” e “As novas regras de financiamento contribuem para a redução das desigualdades no gasto municipal em saúde?".

\section{A vinculação de receitas elevou o gasto em saúde?}

A metodologia utilizada partiu da evolução do gasto total em saúde aplicado pela União, estados e municípios, a fim de verificar se a vinculação da EC 29 contribuiu para aumentar a participação dos governos estaduais e municipais no financiamento da saúde, por meio de recursos próprios 4 . Pretende-se aqui verificar se esse aumento da participação relativa dos governos subnacionais se explica pela queda dos recursos federais ou expansão dos gastos estaduais e municipais em proporção superior ao aumento dos aportes de recursos federais para a saúde.

Para testar tais hipóteses, serão analisados os recursos aplicados pelas três esferas de governo na área da saúde, disponíveis no Sistema de Informações sobre Orçamentos Públicos em Saúde (SIOPS/DATASUS). O período analisado abrange os anos de 1999 a 2006, pois apesar de disponível, o exercício de 1998 não segue a mesma metodologia dos anos posteriores e, por isso, não pôde ser incluído na série histórica analisada.

\section{Os repasses do SUS foram efetuados em proporção à oferta de atenção básica?}

Os repasses federais são condicionados à municipalização da atenção básica (no caso do PAB fixo) e aos programas por eles ofertados (no caso do PAB variável). No caso do PAB fixo, a regulação está apenas na descrição do que ofertar (atendimento básico), mas não há regras sobre a forma de oferta, bem como os repasses são orientados pelo tamanho da população, cabendo aos municípios definir como aplicá-los para prestar a atenção básica de saúde. As transferências do PAB variável, por sua vez, estão condicionadas à oferta de programas específicos, nos moldes definidos pelo Ministério da Saúde. Como a parte variável abrange uma série de programas, tomou-se o PSF como caso exemplar.

Pretende-se verificar se a evolução dos repasses do SUS para a atenção básica (PAB fixo e PAB variável - PSF) foi proporcional à expansão da produção ambulatorial e da cobertura do PSF, ambos sob responsabilidade dos municípios. Observou-se o crescimento anual no período 1999 a 2006, com dados obtidos junto ao SIOPS para os montantes transferidos pelo governo federal, enquanto as informações sobre as ações e serviços prestados pelos governos municipais foram coletadas no Sistema de Informações Ambulatoriais do SUS (SIA/DATASUS).

As novas regras de financiamento contribuem para a redução das desigualdades no gasto municipal em saúde?

Após analisar os efeitos da regulação federal sobre o gasto e sobre a oferta descentralizada, buscou-se avaliar a capacidade desses mecanismos em reduzir as desigualdades no financiamento da saúde mediante o cálculo do coeficiente de Gini. Este indicador varia entre 0 e 1, em que 0 corresponde à completa igualdade de renda e 1 corresponde à completa desigualdade. $\mathrm{O}$ cálculo é efetuado pela área formada entre a curva definida pela distribuição acumulada dos valores observados e a linha de $45^{\circ}$ equidistante entre os eixos, dividida pela área total do triângulo formado pelos eixos e a linha de $45^{\circ}$.

Esse indicador é usado normalmente como medida de desigualdade em relação à distribuição da renda. Todavia, a adaptação foi fácil, uma vez que os municípios podem ser considerados uma população (de 5.560 municípios) que apresenta uma distribuição de gasto per capita em saúde, como se fosse uma "renda per capita". Optou-se por fazer a análise desagregada por fonte de recursos (recursos próprios, transferências do PAB e transferências totais do SUS); para tanto, foi necessário retirar o ano de 1999 da análise, já que os dados desse exercício não estão disponíveis de forma desagregada no SIOPS. O período analisado (2000 a 2006) é, portanto, posterior à introdução dos mecanismos de vinculação de receitas e das transferências condicionadas à oferta descentralizada. Embora não seja possível medir o impacto inicial de tais mecanismos, encontrou-se a tendência estabelecida com estas regras em vigor.

\section{Resultados e discussão}

Nesta parte, serão analisados o ordenamento jurídico-institucional da regulação federal sobre o financiamento da saúde e, na sequência, os resultados obtidos com a vinculação de receitas à saúde (EC 29) e com as normatizações elaboradas pelo Ministério da Saúde. Com foco nos resultados, buscaram-se evidências empíricas para avaliar a eficácia das novas regras e para 
identificar limites colocados ao financiamento da saúde.

Para tanto, a análise está dividida em três partes. A primeira aborda a vinculação de receitas e sua capacidade de mobilizar mais recursos, dos três níveis de governo, para a saúde; a segunda parte avalia as transferências federais aos municípios condicionadas à oferta da atenção básica, verificando se as novas regras foram capazes de compatibilizar recursos e oferta e, por fim, pretende-se verificar se a vinculação de receitas e as transferências condicionadas, em conjunto, reduziram as desigualdades existentes no financiamento da saúde.

\section{Efeitos da vinculação de receitas}

A aprovação da EC 29 objetivava garantir recursos mínimos e estáveis para a saúde. Para isso, essa emenda estabeleceu uma vinculação de receitas de estados e municípios à saúde, tal como já ocorria em relação à educação. Para a União, a exigência era que no primeiro ano (2000), os recursos federais aplicados em saúde fossem $5 \%$ superiores ao valor aplicado no ano anterior e a correção para os anos seguintes seria de acordo com a variação nominal do PIB.

Porém, a ausência de regulamentação dessa emenda abriu margem a interpretações distintas sobre a obrigatoriedade de gasto da União: de um lado, o Ministério da Saúde entendeu que o cálculo deveria ser feito ano a ano, ou seja, o percentual de reajuste do PIB nominal deveria ser aplicado sobre o valor do ano imediatamente anterior ao exercício em questão; por outro lado, o Ministério da Fazenda alegou que o ano-base deveria ser sempre o ano de 1999, acrescido do percentual de variação nominal do PIB. Segundo Marques \& Mendes 5 (p. 167), a diferença entre essas duas interpretações "somou $R$ \$ 1,8 bilhão nos três primeiros anos (2001, 2002 e 2003)”.

Para estados e municípios, a EC 29 previa uma implantação gradual e, inicialmente, exigiu que, no mínimo, 7\% das receitas de impostos e transferências fossem aplicadas em saúde, devendo ser esses percentuais gradualmente ampliados até alcançarem, respectivamente, $12 \%$ e $15 \%$ das receitas estaduais e municipais no ano de 2004. De acordo com Faveret 6, o grande mérito da emenda é, sem dúvida, garantir recursos cativos das três esferas de governo com o financiamento da saúde, dando mais previsibilidade ao seu orçamento.

Em suma, espera-se que a vinculação de receitas eleve a participação dos governos subnacionais no financiamento da saúde, pois o mecanismo faz que as esferas menores de governo cumpram sua parte no financiamento das políticas sociais 7. Em relação à participação da União, em razão da ausência de regulamentação da EC 29 e dos constrangimentos fiscais colocados pela política macroeconômica 8 , espera-se menor participação do gasto federal em saúde.

Para testar essas hipóteses, a Tabela 1 mostra a evolução dos recursos aplicados em saúde por esfera de governo e a Figura 1 revela a participação dos três níveis de governo no financiamento de tal política. Em ambas são considerados os gastos com recursos próprios de cada esfera (excluindo os efeitos da redistribuição promovida pelas transferências intergovernamentais, ou seja, transferências da União para os municípios estão contabilizados como gasto federal).

Tabela 1

Despesas com ações e serviços públicos de saúde, financiadas por recursos próprios de cada esfera de governo, $2000-2006$.

\begin{tabular}{|c|c|c|c|c|c|c|c|c|c|c|c|c|}
\hline \multirow[t]{2}{*}{ Ano } & \multicolumn{3}{|c|}{ Federal } & \multicolumn{3}{|c|}{ Estadual } & \multicolumn{3}{|c|}{ Municipal } & \multicolumn{3}{|c|}{ Total } \\
\hline & $\mathrm{R} \$$ * & $\begin{array}{c}\text { Per } \\
\text { capita }\end{array}$ & $\%$ PIB & $\mathrm{R} \$$ * & $\begin{array}{c}\text { Per } \\
\text { capita }\end{array}$ & $\%$ PIB & $\mathrm{R} \$$ * & $\begin{array}{c}\text { Per } \\
\text { capita }\end{array}$ & $\%$ PIB & $\mathrm{R} \$$ * & $\begin{array}{c}\text { Per } \\
\text { capita }\end{array}$ & $\%$ PIB \\
\hline 2000 & $36.170,54$ & 213,03 & 1,73 & $11.220,32$ & 66,08 & 0,54 & $13.098,96$ & 79,46 & 0,62 & $60.489,82$ & 358,58 & 2,89 \\
\hline 2001 & $37.119,38$ & 215,33 & 1,73 & $13.655,92$ & 79,21 & 0,63 & $15.343,91$ & 90,49 & 0,71 & $66.119,21$ & 385,03 & 3,07 \\
\hline 2002 & $36.830,68$ & 210,92 & 1,67 & $15.302,82$ & 87,64 & 0,70 & $17.896,46$ & 104,48 & 0,81 & $70.029,96$ & 403,03 & 3,18 \\
\hline 2003 & $36.453,14$ & 206,09 & 1,60 & $16.287,97$ & 92,08 & 0,71 & $18.779,78$ & 109,10 & 0,82 & $71.520,90$ & 407,27 & 3,13 \\
\hline 2004 & $40.898,63$ & 228,35 & 1,68 & $20.044,74$ & 111,92 & 0,83 & $20.507,47$ & 118,19 & 0,84 & $81.450,83$ & 458,46 & 3,35 \\
\hline 2005 & $42.969,80$ & 233,31 & 1,70 & $20.293,95$ & 110,18 & 0,80 & $23.856,81$ & 131,73 & 0,94 & $87.120,56$ & 475,22 & 3,44 \\
\hline 2006 & $46.573,83$ & 249,36 & 1,75 & $22.628,60$ & 121,16 & 0,85 & $26.840,24$ & 146,44 & 1,01 & $96.042,67$ & 516,96 & 3,61 \\
\hline
\end{tabular}

Fonte: Sistema de Informações sobre Orçamentos Públicos em Saúde (gasto estadual e municipal); SPO/SE e Fundo Nacional de Saúde (gasto federal).

* Em milhões, com valores reais de agosto de 2009 (IPCA/IBGE). 


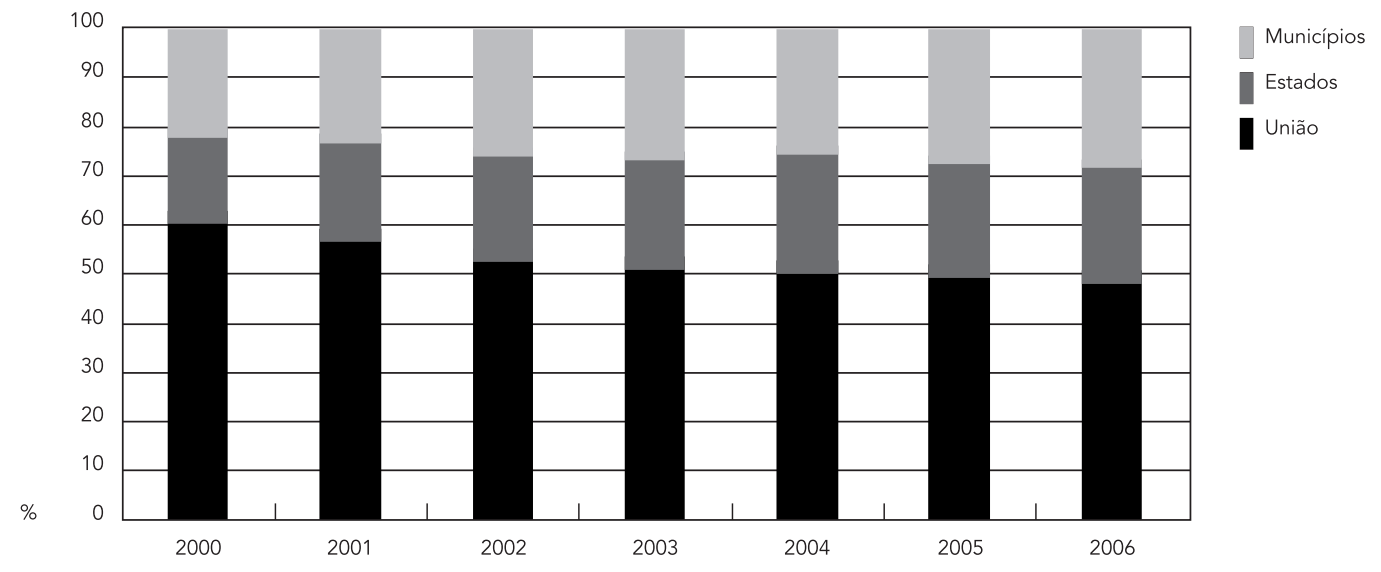

Fonte: Sistema de Informações sobre Orçamentos Públicos em Saúde.

* Em milhões, com valores reais de agosto de 2009 (IPCA/IBGE).

Nota-se que os recursos destinados à saúde cresceram significativamente em valores reais, per capita e em porcentagem do PIB. Somando os esforços das três esferas de governo, o montante aplicado em saúde no ano de 2006 alcançou R\$ 96 bilhões, o que corresponde a R 517 por habitante (em valores atualizados para agosto/2009) e a $3,6 \%$ do PIB, conforme Tabela 1 . O montante total cresceu $58 \%$ no período analisado ou $44 \%$ em termos per capita, o que significa 0,7 p.p. do PIB. Este resultado se deve a um maior esforço dos governos subnacionais, especialmente após a EC 29 .

Os recursos próprios dos governos estaduais tiveram significativa expansão nos anos posteriores à EC 29: o montante aplicado dobrou e o valor per capita subiu mais de $80 \%$, o que representou um aumento de 0,3 p.p. do PIB, e quase a totalidade do crescimento ocorreu até 2004 . Esse resultado surpreende, pois os governos estaduais eram acusados de não cumprir com sua parte no financiamento da saúde, por conta da ausência de regulamentação da EC 295.

Todavia, deve-se ressaltar que a forte expansão ocorreu num patamar baixo de gasto, já que os governos estaduais são aqueles que menos contribuem para o financiamento da saúde. A Figura 1 mostra que os recursos estaduais, apesar da expansão observada, respondem por menos de $25 \%$ do gasto total em saúde e boa parte é direcionada aos procedimentos de média e alta complexidade.
Por sua vez, os governos municipais foram aqueles que mais aumentaram seus gastos em saúde com recursos próprios: o crescimento foi de $105 \%$ e de quase $85 \%$, em termos per capita, o que resultou em uma elevação de 0,4 p.p. do PIB. Com isso, a participação do gasto municipal no financiamento da saúde cresceu de $22 \%$ em 2000 para 28\% em 2006 (Figura 1).

Já os recursos aplicados pela União tiveram aumento real no período 2000-2006, tanto em valores absolutos (29\%), quanto em valores per capita $(17 \%)$, mas o crescimento real foi bem inferior ao encontrado nas esferas estaduais e municipais, sendo incapaz de elevar a proporção do gasto federal em saúde no PIB. Consequentemente, a participação da União no financiamento dessa política diminuiu, passando de $60 \%$ em 2000 para $48 \%$ em 2006.

Além disso, a trajetória do gasto federal em saúde - em valores absolutos, per capita e em proporção do PIB - é bastante errática e pode ser subdividida em duas partes: (i) de 2000 a 2003, o gasto federal ficou estagnado em valores absolutos e apresentou queda em valores per capita e em relação ao PIB, e foi neste período que os gastos estaduais e municipais cresceram mais; (ii) entre 2004 e 2006, verificou-se uma expansão significativa dos gastos federais em saúde, o que reflete maior esforço por parte da União nesses anos.

No período como um todo, apesar da trajetória irregular, houve aumento real nos repasses 
federais, que poderia ter sido maior, porque o percentual em relação ao PIB não aumentou. Por outro lado, ocorreu forte expansão dos recursos estaduais e, sobretudo, municipais destinados à saúde, refletindo os efeitos da vinculação dos recursos dessas esferas imposta pela EC 29, elevando a participação de cada esfera no financiamento da política.

\section{Efeitos das transferências condicionadas}

As NOB 01/93 e NOB 01/96 estabeleceram a atenção básica como foco da política e definiram uma série de processos automáticos de descentralização de recursos condicionados à oferta de programas considerados prioritários pelo Ministério da Saúde. Segundo Cajueiro ${ }^{9}$, mesmo após a NOB 01/93, a incerteza acerca da capacidade de o Ministério da Saúde cumprir com os repasses previstos tornava arriscado assumir responsabilidades que implicassem despesas adicionais significativas. Logo, ainda faltavam regras claras e incentivos mais fortes - particularmente no lado financeiro - para que os municípios assumissem a gestão da política de saúde.

Para promover a efetiva descentralização da atenção básica à saúde, foi editada a NOB 01/96, que estabeleceu apenas dois tipos de gestão municipal em saúde: (i) a gestão plena de atenção básica, em que os municípios ficam responsáveis pela oferta das especialidades básicas, pela gestão das unidades básicas de saúde e pelas ações de vigilância sanitária e epidemiológica e; (ii) a gestão plena do sistema de saúde que, além das ações de atenção básica incluídas no primeiro tipo de gestão, inclui a gestão dos serviços de alta e média complexidade 10 .

Esta nova regulação também promoveu uma mudança na lógica dos repasses por meio das transferências fundo a fundo para o atendimento da atenção básica, tendo como referência um valor per capita previamente fixado, multiplicado pelo número de habitantes de cada município, compondo dessa forma o Piso Assistencial Básico (PAB).

A adoção do PAB eliminou dois pontos principais de resistência dos municípios: a incerteza quanto à regularidade dos repasses federais e a dissociação deles em relação à produção de serviços. Prova disso é que $99 \%$ dos municípios estavam habilitados a um dos dois tipos de gestão em 2001, sendo 89,1\% na atenção básica e 10,1\% na gestão plena do sistema municipal 9 .

Mesmo prevendo receitas adicionais em caso de adesão dos municípios a certos programas desenhados nacionalmente, os recursos ainda eram repassados em um único bloco, fato que dificultava o controle do destino dos recursos e a efetiva expansão da oferta dos programas específicos, definidos como prioritários pelo Ministério da Saúde.

O caminho então foi transformar o Piso Assistencial Básico no Piso da Atenção Básica (que também ficou conhecido como PAB) e subdividilo em duas partes: (i) o PAB fixo, que é calculado com base em um valor per capita multiplicado pela população de cada município, cujos recursos devem ser utilizados para o atendimento das especialidades de atenção básica; (ii) o PAB variável corresponde a incentivos financeiros especiais para programas prioritários definidos pelo governo federal, por exemplo, o PSF e o Programa de Agentes Comunitários de Saúde (PACS) 11.

De acordo com Arretche 12 (p. 452), utilizouse "de um conjunto sucessivo de portarias ministeriais, a partir das quais a burocracia do Ministério da Saúde foi progressivamente organizando uma estrutura de incentivos destinada a obter a adesão dos municípios aos objetivos da reforma". Segundo Viana \& Machado 13 (p. 812), esses incentivos foram sendo moldados pela elaboração de "novas modalidades de transferência de recursos (per capita e por programas específicos) e instrumentos para priorizar a descentralização da atenção básica e incentivar a oferta de programas definidos como prioritários pelo Ministério da Saúde".

As transferências condicionadas podem induzir à descentralização, pois condicionam os repasses à oferta descentralizada de certos programas ${ }^{14}$, representando um forte estímulo para a adesão municipal ${ }^{15}$. Diante disso, aconteceu aumento da oferta municipal de serviços de atenção básica à saúde? Quanto ao financiamento, objeto central deste estudo, os repasses acompanham a expansão da oferta desses serviços ofertados pelos municípios?

As Figuras 2 e 3 fazem o cruzamento entre o crescimento real dos repasses $\mathrm{PAB}$ fixo e variável (PSF) e a evolução da oferta descentralizada no período 1998 a 2006, que será mensurada valendo-se de três indicadores: (i) a produção ambulatorial de atendimento básico; (ii) o número de visitas realizadas pelas equipes de saúde da família e; (iii) o número de famílias acompanhadas pelo programa.

Ambos os gráficos demonstram que nos primeiros anos de implantação dos programas, quando a adesão dos municípios precisa ser efetivada, as transferências de recursos federais cresceram em proporção superior à produção municipal de serviços de saúde. Nos anos seguintes, observou-se que o crescimento real dos repasses ficou abaixo (no caso do PAB fixo) ou apenas acompanhou (no caso do PAB variável PSF) a expansão da oferta de ações de saúde. 
Taxa anual de crescimento dos repasses do PAB fixo e da produção ambulatorial de atendimento básico (prestador municipal), 1999-2006.

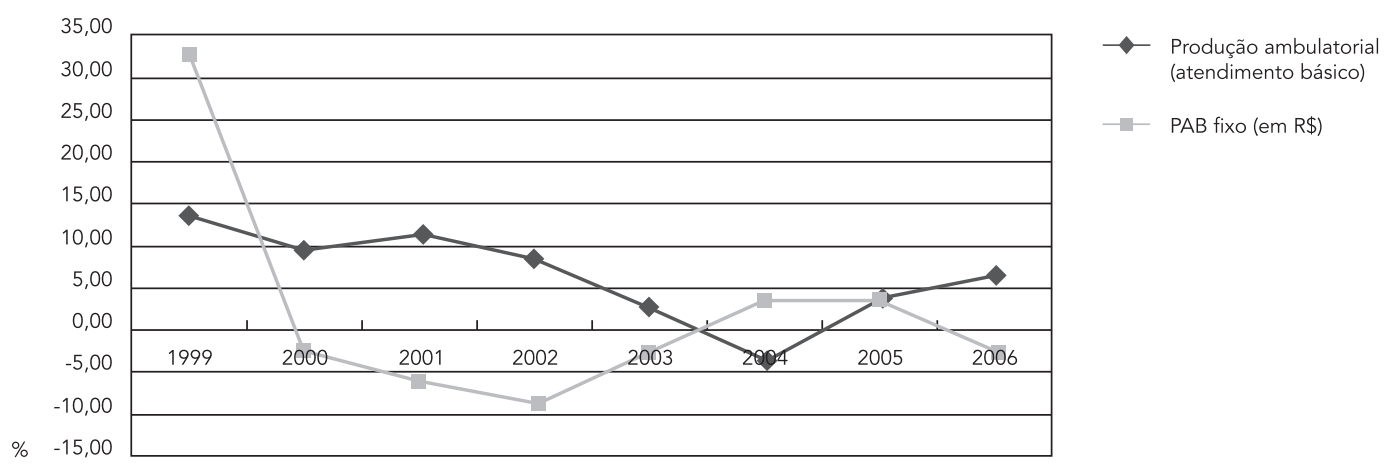

Fonte: Sistema de Informações sobre Orçamentos Públicos em Saúde e Sistema de Informações Ambulatoriais do SUS.

Nota: valores reais de agosto de 2009, corrigidos pelo IPCA/IBGE.

\section{Figura 3}

Taxa anual de crescimento dos repasses do PAB variável - PSF, da quantidade de visitas e do número de famílias atendidas, 1999-2006.

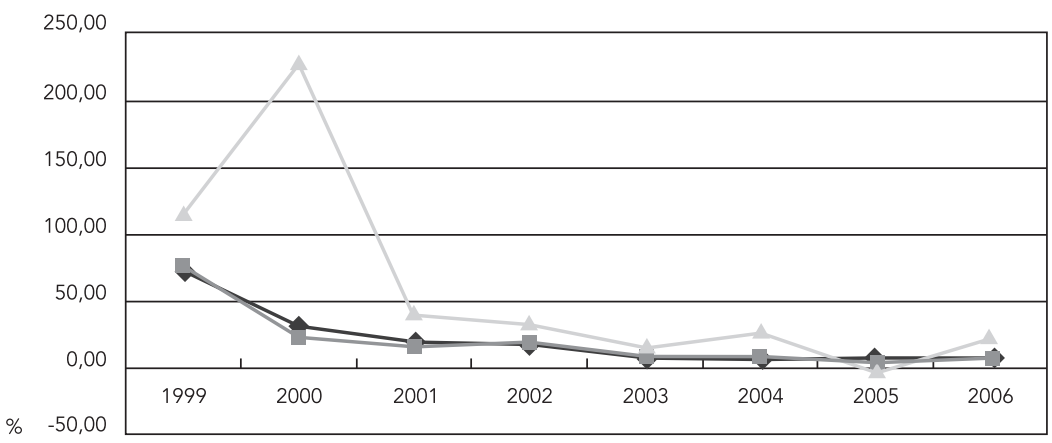

\footnotetext{
$\longrightarrow$ Número de visitas

$\rightarrow$ Número de famílias atendidas

- PAB variável - PSF (em R\$)
}

Fonte: Sistema de Informações sobre Orçamentos Públicos em Saúde e Sistema de Informações Ambulatoriais do SUS.

Nota: valores reais de agosto de 2009, corrigidos pelo IPCA/IBGE.

A trajetória dos recursos transferidos pelo PAB fixo é bastante exemplar (Figura 2). Entre 1998 e 1999, existiu um salto significativo superior a $30 \%$ desses repasses, reflexo da forte adesão à gestão plena de atenção básica, o que resultou no crescimento de $13,6 \%$ na produção ambulatorial prestada pelos sistemas municipais de saúde, e os recursos adicionais superaram essa expansão da oferta.
Depois de efetivada a descentralização, houve queda da transferência em valores reais entre 2000 e 2003, enquanto a produção ambulatorial de atendimento básico prestado pelos sistemas municipais de saúde continuava a crescer ano após ano. Em 2004 e 2005, houve uma recuperação dos valores transferidos pelo $\mathrm{PAB}$ fixo, mas em 2006, novamente, constatou-se uma queda real nos repasses. 
O comportamento das transferências do PAB fixo é explicado pela correção inadequada do valor per capita que serve como referência para os repasses (por meio da multiplicação do valor pelo tamanho da população de cada município). Entre 1998 e 2003, o valor do PAB fixo ficou congelado e também não ocorreu a correção do número de habitantes dos municípios. Para os anos seguintes, o Ministério da Saúde promoveu correções da base populacional e o valor per capita subiu para R\$13,00 em 2004, R\$ 15,00 em 2006, R\$ 16,00 em 2008 e R \$ 17,00 em 2009. Apesar desses reajustes, o valor de 2009 deveria ser de $\mathrm{R} \$ 20,50$, caso o mesmo fosse corrigido pela inflação acumulada de janeiro de 1998 (IPCA).

Em relação às transferências do $\mathrm{PAB}$ variável para a oferta do PSF pelos municípios (Figura 3), é possível notar que a expansão mais forte dos recursos federais também ocorreu nos anos iniciais, quando os governos municipais estavam aderindo ao programa, podendo contar com recursos adicionais repassados pelo SUS para sua implantação. Em 1999 e 2000, o número de famílias atendidas pelo PSF cresceu $76 \%$ e $23 \%$, respectivamente; ao passo que os repasses correspondentes do PAB variável aumentaram 114\% e $227 \%$, vale dizer, os recursos cresceram bem mais que a oferta neste primeiro momento.

Nos anos seguintes (2001 a 2006), os recursos transferidos aumentaram apenas em proporção à expansão da cobertura do programa, sem repetir o ritmo de expansão observado nos anos iniciais do programa. Esse ritmo mais moderado está relacionado à ausência de correção adequada dos valores-referência para os repasses do programa. Caso o IPCA fosse aplicado, o valor repassado por equipe deveria ser de R\$ 9 mil mensais em 2009 (modalidade 2), porém o valor que vigorou foi de $\mathrm{R} \$ 6$ mil.

Notou-se, portanto, que as transferências condicionadas buscaram conquistar a "cooperação" dos municípios com repasses mais generosos no começo, funcionando como "isca" para a adesão deles. A perspectiva de uma fonte adicional e estável de recursos forneceu incentivos necessários para a descentralização da atenção básica. Após os municípios terem assumido a oferta, as transferências do PAB fixo cresceram aquém do esperado, pois os valores per capita que norteiam os repasses não foram adequadamente corrigidos, enquanto os recursos do $\mathrm{PAB}$ variável - PSF apenas acompanharam a expansão da cobertura do programa.

Tendo em vista que as demandas sociais pelas ações e serviços de saúde em questão e os custos de oferta dos programas continuaram crescendo, foi preciso aumentar a parcela de recursos próprios municipais destinada ao financiamento da atenção básica, o que requer o aumento da participação dos municípios no financiamento da saúde, pela aplicação de percentuais cada vez mais elevados de suas receitas em ações e serviços de saúde 16. Daí a importância da vinculação de receitas para cativar recursos dos orçamentos dos governos subnacionais para a área da saúde.

Há, pois, uma complementaridade entre tais mecanismos. Ela repousa sobre a diferença entre os valores repassados e os recursos necessários para cobrir integralmente os custos de oferta dos programas, o que exige contrapartidas com recursos próprios (municipais, no caso da atenção básica), viabilizados pela vinculação de receitas. De um lado, a vinculação de receitas impõe restrição direta à autonomia dos governos locais, a fim de mobilizar mais recursos estaduais e municipais para a saúde. Do outro lado, as transferências condicionadas fornecem incentivos financeiros para que os municípios assumam a oferta de programas, pois, embora insuficientes, elas subsidiam o custo de oferta, o que ajuda no financiamento dos programas executados localmente, sob regras definidas centralmente.

Em suma, vinculação de receitas e transferências condicionadas à oferta atuaram conjuntamente para aumentar os gastos em saúde dos governos subnacionais e para promover a efetiva descentralização da atenção básica, nos moldes definidos pelo Ministério da Saúde. Resta saber se esses mecanismos, em conjunto, também contribuíram para a correção das desigualdades horizontais no gasto em saúde aplicado pelos municípios.

\section{Efeitos sobre as desigualdades}

Em relação às desigualdades no financiamento da saúde, a EC 29 contribui para a redução das diferenças nos valores aplicados em saúde, pois equaliza com um percentual obrigatório de gasto 4,6. Quanto aos mecanismos de transferências do SUS, alguns estudos apontam para a redução das desigualdades na alocação per capita de recursos federais destinados à atenção básica 11,17, enquanto outros consideram que as regras introduzidas pelo PAB são insuficientes, por conta da ausência de critérios que contemplem diferentes perfis demográficos, epidemiológicos e condições sociossanitárias e que estejam orientadas para as maiores "necessidades de saúde" 18.

Com o intuito de mensurar o tamanho da desigualdade e tendência observada com os mecanismos de regulação analisados em vigor, a Figura 4 mostra os coeficientes de Gini referentes à distribuição do gasto per capita total aplicado por cada município no período 2000 a 2006, com dados desagregados segundo a fonte: gasto 


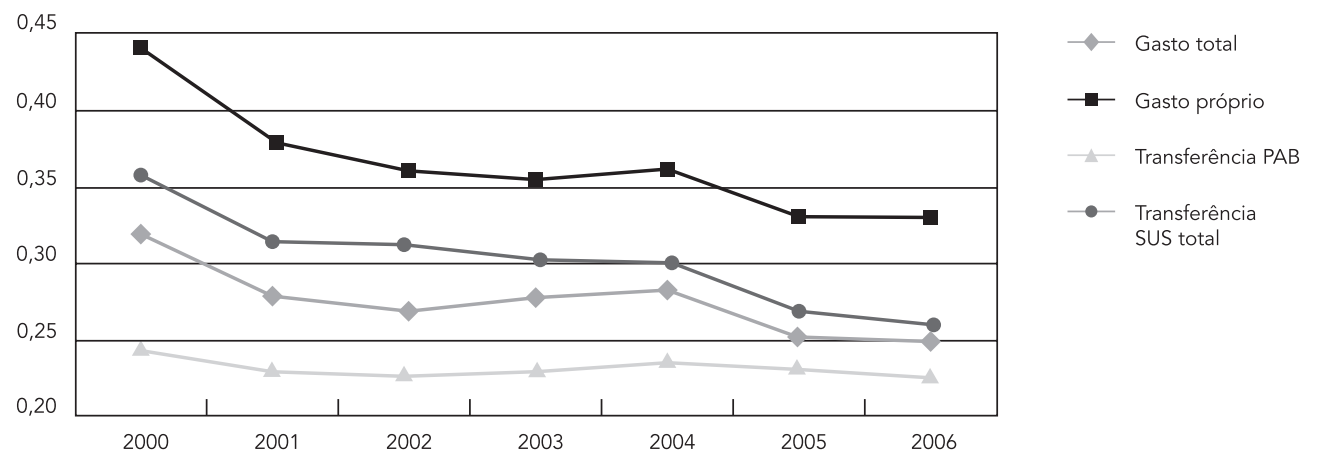

Fonte: Sistema de Informações sobre Orçamentos Públicos em Saúde.

próprio, transferências do PAB (fixo e variável) e transferências totais do SUS (inclusive, o PAB).

Nota-se uma significativa queda na desigualdade horizontal em relação ao gasto per capita total aplicado por cada município no período analisado, explicada pela redução das diferenças em relação ao gasto próprio e também à distribuição mais equânime das transferências do SUS, especialmente em relação ao PAB fixo e variável.

No primeiro caso, defende-se aqui que a queda da desigualdade está relacionada com a vinculação das receitas municipais ao financiamento da saúde. O coeficiente de Gini do gasto próprio em saúde sofreu forte inflexão para baixo nos anos de implantação da vinculação (especialmente até 2003), dado que, com a ampliação gradual do percentual mínimo destinado à saúde, elevou-se o patamar de gasto daqueles municípios que aplicavam um percentual inferior.

O percentual mínimo acabou servindo como referência para os municípios como um todo, apesar da ausência de impedimentos aos governantes de destinar parcelas maiores dos seus orçamentos à saúde. Após a EC 29, as desigualdades no gasto em saúde passam a ser mais explicadas pelas diferenças na capacidade fiscal de cada município (quanto aos recursos disponíveis) do que pela decisão de gasto dos governantes que passou a ser condicionada pela regulação federal.

Em relação às transferências do SUS, percebe-se também uma acentuada queda da desigualdade entre os municípios brasileiros em função dos critérios redistributivos que norteiam esses repasses.
A distribuição dos repasses do PAB (fixo e variável) em valores per capita apresenta a menor desigualdade. De um lado, as transferências do PAB fixo são definidas por um valor per capita, com uma pequena variação de acordo com as características dos municípios. Por outro lado, as transferências condicionadas do PAB variável dependem da adesão e da expansão da oferta municipal dos programas definidos como prioritários e, como houve expansão da oferta descentralizada como um todo, as diferenças se mantêm baixas.

Quando as demais transferências do SUS são somadas, verifica-se um padrão de distribuição ainda menos desigual que os gastos com recursos próprios, mas com coeficientes de Gini maiores, se comparados com os repasses exclusivos do PAB. Isso se explica pelas características dos demais repasses do SUS, como no caso da alta e média complexidade, que ainda guardam relações com a produção ex-ante de atendimento médico-hospitalar, pois segue a lógica anterior de financiamento que privilegiava municípios economicamente mais desenvolvidos 19 que, por sua vez, acabam atendendo pacientes de outros municípios.

No entanto, deve-se ressaltar que a desigualdade no gasto total em saúde é menor que as desigualdades encontradas em cada fonte de recursos (próprios e transferências SUS, total) separadamente. Isso se deve ao fato de as duas fontes serem complementares: os municípios que recebem mais recursos das transferências do SUS são aqueles com menor capacidade de gasto próprio por habitante, sobretudo por con- 
ta da distribuição bastante equânime dos repasses do PAB. Novamente, os dois mecanismos se complementam e colaboram para reduzir a desigualdade horizontal no gasto em saúde como um todo.

\section{Considerações finais}

Este artigo demonstrou como os mecanismos de regulação - vinculação de receitas e transferências condicionadas - foram implementados e quais os impactos observados no financiamento da saúde, destacando a expansão dos gastos estaduais e municipais nessa política e a redução das desigualdades nos recursos per capita disponíveis aos municípios para o custeio das ações e serviços de saúde descentralizados.

As transferências condicionadas exerceram seu papel de coordenação federativa, pois forneceram os incentivos necessários para a implantação de políticas nacionais descentralizadas, as quais são desenhadas centralmente, e implantadas localmente. Já a vinculação de receitas afetou mais diretamente a decisão de gasto dos governos subnacionais ao cativar recursos disponíveis dessas esferas para o financiamento da saúde 3 . Com a realização deste trabalho, constatou-se que os dois mecanismos se complementaram e conseguiram elevar a participação dos governos subnacionais no financiamento da saúde e reduzir as desigualdades horizontais no plano nacional.

Nos anos iniciais, quando o governo federal busca a adesão dos governos municipais, os valores repassados cobrem uma parcela significativa dos custos, o que dá incentivos para que os municípios implantem os programas selecionados, pois irão contar com recursos adicionais para cobrir (parcialmente) os custos do programa.

Os repasses federais tendem a crescer bastante nos anos iniciais, pois reflete a adesão em massa dos municípios. Porém, nos anos seguintes, após a implantação dos programas na grande maioria dos municípios, os valores repassados pelo governo federal não sofrem as cabíveis correções e, consequentemente, as transferências do PAB fixo e variável diminuem, bem como a participação relativa da União no financiamento da saúde como um todo. Tais fatos são evidências empíricas fortes dos constrangimentos fiscais colocados ao gasto social federal 5,8.

Em contrapartida, os custos de oferta dos programas cresceram no período, o que exige aportes de recursos de outras fontes. Diante disso, a vinculação de receitas à saúde serviu para viabilizar recursos próprios à expansão das contrapartidas municipais. De um lado, os municípios não podem deixar de ofertar o programa, pois já existe forte pressão social para a sua continuidade. Do outro lado, os repasses ainda continuam importantes para o financiamento dos programas, o que obriga os municípios a continuarem a ofertá-los, seguindo as diretrizes traçadas centralmente.

Esses dois mecanismos - vinculação de receitas e transferências condicionadas - também são complementares quanto aos efeitos equalizadores do gasto per capita municipal. Por meio da aplicação do coeficiente de Gini, constatou-se que a desigualdade do gasto com recursos próprios e com transferências do SUS caíram significativamente, com destaque para a distribuição bastante equânime dos repasses do PAB. Quando os gastos com recursos próprios e com as transferências do SUS são somados, a desigualdade do gasto consolidado se torna menor e com uma queda mais acentuada no período analisado.

Em suma, conclui-se que a vinculação de receitas e a normatização das transferências federais condicionadas à oferta de ações de atenção básica resultaram em aumento do gasto total em saúde, puxado por uma expansão mais forte dos gastos próprios dos governos municipais e em forte diminuição das desigualdades horizontais nos recursos aplicados pelos municípios no financiamento da saúde. 


\section{Resumo}

O objetivo deste artigo é analisar os impactos da vinculação de receitas e das transferências condicionadas à oferta sobre o financiamento da saúde. Após analisar o papel desempenhado por esses mecanismos de regulação federal sobre a gestão descentralizada da atenção básica em saúde, optou-se por verificar seus efeitos sobre a trajetória do gasto total em saúde, desagregado por esfera de governo; avaliar se os repasses do SUS acompanharam a evolução da oferta descentralizada; e mensurar as desigualdades entre os valores per capita aplicados em saúde pelos municípios brasileiros. As conclusões mostram uma complementaridade entre vinculação de receitas e transferências condicionadas à oferta que: (1) aumentou a participação dos governos subnacionais no financiamento da saúde; (2) forneceu incentivos para a descentralização da atenção básica, segundo diretrizes definidas centralmente e; (3) reduziu as desigualdades em relação ao gasto per capita em saúde dos municípios.

Financiamento em Saúde; Regulamentação Governamental; Descentralização; Atenção Primária à Saúde

\section{Referência}

1. Castro ALB, Machado CV. A política de atenção primária à saúde no Brasil: notas sobre a regulação e o financiamento federal. Cad Saúde Pública 2010; 26:693-705.

2. Levcovitz E, Lima LD, Machado CV. Política de saúde nos anos 90: relações intergovernamentais e o papel das Normas Operacionais Básicas. Ciênc Saúde Coletiva 2001; 6:269-91.

3. Machado CV, Baptista TWF, Lima LD. O planejamento nacional da política de saúde no Brasil: estratégias e instrumentos nos anos 2000. Ciênc Saúde Coletiva 2010; 15:2367-82.

4. Campelli MGR, Calvo MCM. O cumprimento da Emenda Constitucional no. 29 no Brasil. Cad Saúde Pública 2007; 23:1613-23.

5. Marques RM, Mendes A. Os dilemas do financiamento do SUS no interior da seguridade social. Economia e Sociedade 2005; 24:159-75.

\section{Agradecimentos}

Agradeço a Marta Arretche, Eduardo Fagnani, Sérgio Prado e Geraldo Di Giovanni pelos comentários e sugestões ao texto.
6. Faveret ACSC. A vinculação constitucional de recursos para a saúde: avanços, entraves e perspectivas. Ciênc Saúde Coletiva 2003; 8:371-8.

7. Vianna S. A seguridade social e o SUS: revisitando o tema. Saúde Soc 2005; 14:7-22.

8. Castro JA, Ribeiro JA, Chaves JV, Duarte BC, Simões HB. Gasto social e política macroeconômica: trajetórias e tensões no período 1995-2005. Brasília: Instituto de Pesquisa Econômica Aplicada; 2008. (Texto para Discussão, 1324).

9. Cajueiro JPM. Saúde Pública no Brasil nos anos noventa: um estudo da política e de seus limites e condicionantes macroeconômicos [Dissertação de Mestrado]. Campinas: Instituto de Economia, Universidade Estadual de Campinas; 2004. 
10. Andrade LOM, Barreto ICHC. SUS passo a passo: história, regulamentação, financiamento e políticas nacionais. 2a Ed. São Paulo: Editora Hucitec; 2007.

11. Melamed C, Costa NR. Inovações no financiamento à Atenção Básica. Ciênc Saúde Coletiva 2003; 8:393-401.

12. Arretche M. Federalismo e relações intergovernamentais no Brasil: a reforma de programas sociais. Dados Rev Ciênc Sociais 2002; 45:431-58.

13. Viana ALd'A, Machado CV. Descentralização e coordenação federativa: a experiência brasileira na saúde. Ciênc Saúde Coletiva 2009; 14:807-17.

14. Prado S. A questão fiscal na Federação Brasileira: diagnósticos e alternativas. Brasília: Instituto de Pesquisa Econômica Aplicada/Comissão Econômica para a América Latina e o Caribe, 2007.

15. Scatena JHG, Viana ALd'A, Tanaka OY. Sustentabilidade financeira e econômica do gasto público em saúde no nível municipal: reflexões a partir de dados de municípios mato-grossenses. Cad Saúde Pública 2009; 25:2433-45.
16. Lima LD, Andrade CLT. Condições de financiamento em saúde nos grandes municípios do Brasil. Cad Saúde Pública 2009; 25:2237-48.

17. Souza RR. Redução das desigualdades regionais na alocação dos recursos federais para a saúde. Ciênc Saúde Coletiva 2003; 8:449-60.

18. Porto SM. Equidad y distribución geográfica de recursos financieros en los sistemas de salud. Cad Saúde Pública 2002; 18:939-57.

19. Lima LD. Conexões entre o federalismo fiscal e o financiamento da política de saúde no Brasil. Ciênc Saúde Coletiva 2007; 12:511-22.

Recebido em 23/Nov/2010

Versão final reapresentada em 26/Mar/2011

Aprovado em 07/Abr/2011 